\title{
Phylogenetic Studies on the Synaptic Vesicle Glutamate Transport System
}

\author{
Joel S. Tabb ${ }^{1}$ and Tetsufumi Ueda ${ }^{1,2}$ \\ 'Mental Health Research Institute and ${ }^{2}$ Departments of Pharmacology and Psychiatry, The University of Michigan, Ann \\ Arbor, Michigan 48109
}

The ATP-dependent uptake of glutamate into synaptic vesicles isolated from mammalian brains is well characterized. Glutamate uptake requires an electrochemical proton gradient, is specific for glutamate over other amino acids, and is stimulated by chloride. To determine whether these characteristics are fundamental to the vesicular uptake system, vesicles were isolated from the brain and central nervous ganglia of several vertebrate and invertebrate species, which included goldfish, frogs, turtles, pigeons, rats, Drosophila, and crayfish, and these vesicles were assayed for glutamate uptake activity. ATP-dependent glutamate was found in all of the vertebrate species tested, but was not detected in Drosophila or crayfish vesicles. The nature of the vesicular uptake of glutamate was similar among all the vertebrates: the specificity for glutamate remained high, transport was energized by a vacuolar (V)-type ATPase, 2-4 mM chloride stimulated uptake three- to sixfold, and $K_{m}$ for glutamate was between 0.5 and $2 \mathrm{~mm}$. While these major characteristics of the uptake system remained conserved among the vertebrates tested, minor differences were seen in glutamate specificity, the steady-state level of glutamate obtained in the vesicles, and $\boldsymbol{V}_{\max }$ of the glutamate uptake systems. These results indicate that the synaptic vesicle glutamate uptake system is present throughout the vertebrate class, and that while minor changes in the transport system have occurred, its major functional characteristics, such as stimulation by chloride and strict substrate specificity, have been conserved for over 350-400 million years.

It is well established that neurotransmitters such as catecholamines, glutamate, GABA, and glycine are readily accumulated in an ATP-dependent manner into synaptic vesicles within the CNS (Philippu and Beyer, 1973; Toll et al., 1977; Naito and Ueda, 1983, 1985; Fykse and Fonnum, 1988; Hell et al., 1988; Kish and Ueda, 1989; Floor et al., 1990). However, the role of synaptic vesicles in release of these neurotransmitters in the CNS has not been firmly established. Studies by Nicholls and Sihra (1986) strongly suggest that the exocytotic pool of glutamate originates from a noncytosolic site within the nerve terminal, and recent evidence by Kish and Ueda (1991) points to

\footnotetext{
Received Dec. 4, 1990; accepted Jan. 25, 1991.

We are grateful to Dr. E. Floor for the bafilomycin and to Dr. P. E. Kish for his valuable comments on the manuscript. This study was supported by NIH Grant NS 26884 and by Alcohol, Drug Abuse, and Mental Health Administration Postdoctoral Fellowship MH 15794-12 to J.S.T.

Correspondence should be addressed to T. Ueda, Mental Health Research Institute, The University of Michigan, 205 Washtenaw Place, Ann Arbor, MI 48109. Copyright (C) 1991 Society for Neuroscience $0270-6474 / 91 / 111822-07 \$ 03.00 / 0$
}

synaptic vesicles as the source of the glutamate that is released in a calcium-dependent manner from nerve terminals.

Because the vesicular pool of glutamate appears to be involved in glutamatergic synaptic transmission, it will be important to understand the role of glutamate transport in this event. The transport of glutamate into synaptic vesicles has been well characterized, and both active uptake (Naito and Ueda, 1985) and facilitative efflux (Carlson and Ueda, 1990) of glutamate have been shown to occur readily in isolated mammalian brain synaptic vesicles. The uptake of glutamate into mammalian synaptic vesicles is driven by an electrochemical membrane potential that is generated by a vacuolar (V)-type (ATPase nomenclature is that of Petersen and Carafoli, 1987) protonpump ATPase (Naito and Ueda, 1985; Maycox et al., 1988; Shioi et al., 1989; Cidon and Sihra, 1989). The ATP-dependent glutamate uptake system is stimulated by chloride and is specific for glutamate over other amino acids, neurotransmitters, or glutamate receptor agonists/antagonists; it also has an unusually high $\mathrm{K}_{\mathrm{m}}$ (about 1-2 mM) for uptake (Naito and Ueda, 1985; Kish and Ueda, 1989). These characteristics are in contrast to those of the brain plasma membrane glutamate transport system, which is sodium dependent, accepts aspartate as well as glutamate, and has a $\mathrm{K}_{\mathrm{m}}$ for uptake in the 3-20 $\mu \mathrm{M}$ range (Logan and Snyder, 1972; Kanner and Sharon, 1978; Christensen and Makowske, 1983).

The role of chloride stimulation, stringent substrate selectivity, and low substrate affinity is not well understood. To determine whether these characteristics are fundamental to the function of glutamatergic synaptic vesicles in all species or are unique to mammalian brain vesicles, we have examined the transport of glutamate into synaptic vesicles isolated from evolutionarily diverse organisms. We have found that, though small differences are present among the vertebrate species examined, the major characteristics of vesicular glutamate transport remain conserved throughout vertebrate evolution.

\section{Materials and Methods}

Materials. Frogs were purchased from Sullivan Co., Nashville, TN, or Kons Scientific, Germantown, WI. Turtles were from Dr. D. Dawson, Department of Physiology, The University of Michigan, and goldfish were from Dr. R. Davis, Neuroscience Laboratory, The University of Michigan. Pigeons were purchased from Palmetto Pigeon Farm, Sumter, SC. Crayfish were purchased from a local fish market, and Drosophila heads, thoraxes, and abdomens were a generous gift of Dr. K. Ikeda, Beckman Research Institute, City of Hope, CA.

All glutamate analogs and agonists, ATPase inhibitors, and assay chemicals were purchased from Sigma, with the exception of bafilomycin, which was a generous gift of Dr. Erik Floor (Department of Physiology and Cell Biology, University of Kansas), which was supplied 
by Dr. K. Altendorf (Universität Osnabrück, Germany). L-[2,3- $\left.{ }^{3} \mathrm{H}\right]$ glutamate $(50 \mathrm{Ci} / \mathrm{mmol})$ was purchased from Amersham.

Preparation of crude synaptic vesicles. Crude synaptic vesicles were prepared as specified in Kish and Ueda (1989). Bricfly, Drosophila heads, thoraxes, and abdomens; crayfish central nervous ganglia; and whole brains from goldfish, frogs, turtles, pigeons, and rats were removed and homogenized in solution $\mathrm{A}(0.32 \mathrm{M}$ sucrose, $0.5 \mathrm{~mm}$ calcium acetate, 1 $\mathrm{mm}$ magnesium acetate, and $\left.1 \mathrm{~mm} \mathrm{NaHCO}_{3}\right)$. The homogenate was centrifuged at $12,100 \times g_{\max }$ for $20 \mathrm{~min}(10,000 \mathrm{rpm}$; Sorvall SS-34 rotor). The pellets were lysed for $45 \mathrm{~min}$ in $6 \mathrm{~mm}$ Tris-maleate $(\mathrm{pH}$, $8.1)$ and centrifuged at $43,500 \times g_{\max }$ for $15 \mathrm{~min}(19,000 \mathrm{rpm}$; Sorvall SS-34 rotor). The supernatant was centrifuged at $200,000 \times g_{\max }$ for 60 min (43,000 rpm; Beckman Ti45 rotor), and the crude synaptic vesicle pellets were resuspended in solution $B(0.32 \mathrm{M}$ sucrose, $1 \mathrm{~mm}$ dithiothreitol, and $1 \mathrm{~mm} \mathrm{NaHCO}$ ). Synaptic vesicles were stored in liquid nitrogen for up to 6 months, with no loss of glutamate uptake activity.

Assay for glutamate transport activity. Vesicular glutamate uptake was measured as described previously (Kish and Ueda, 1989). The standard uptake assay mixture (100 $\mu$ l final volume) contained $10-50 \mu \mathrm{g}$ crude vesicle protein, $0.25 \mathrm{M}$ sucrose, $10 \mathrm{~mm}$ HEPES ( $\mathrm{pH}, 7.4), 4 \mathrm{~mm} \mathrm{MgSO}_{4}$, $4 \mathrm{mM} \mathrm{KCl}, 2 \mathrm{~mm}$ potassium aspartate (HEPES/sucrose media), 0 or 2 mM Tris-ATP, and $0.5 \mathrm{~mm}$ potassium ${ }^{3} \mathrm{H}$-glutamate $(4 \mu \mathrm{Ci})$. Crude vesicles $(10 \mu \mathrm{l})$ and HEPES/sucrose media $(70 \mu \mathrm{l})$ were prewarmed to $30^{\circ} \mathrm{C}$, and the uptake reaction was initiated by the rapid addition of ${ }^{3} \mathrm{H}$ glutamate with or without ATP $(20 \mu 1)$. Unless stated otherwise, the reaction mixture was incubated for $10 \mathrm{~min}$, and uptake was quenched by the addition of $2.0 \mathrm{ml}$ of ice-cold $0.15 \mathrm{M} \mathrm{KCl}$, followed immediately by filtration through Millipore HAWP filters $(25 \mathrm{~mm}, 0.45 \mu \mathrm{m})$. The assay tubes were washed twice with $\mathrm{KCl}$ solution, and the filters were washed three more times with $\mathrm{KCl}$. The radioactivity retained on the filter was counted in Cytoscint ES scintillation cocktail (ICN, Costa Mesa, CA) using a Beckman LS 9000 liquid scintillation spectrophotometer. All values are corrected for the nonspecific ${ }^{3} \mathrm{H}$-glutamate that bound to filters. Synaptic vesicle protein was determined according to Lowry et al. (1951) using bovine serum albumin as a standard.

Kinetic parameters were derived using a FORTRAN program described by Cleland (1979). The program applies the Gauss-Newton nonlinear least-square method to fit the data to

$$
\log v=\log \left(V_{\max } \cdot[S] /\left(K_{m}+[S]\right)\right),
$$

where $v$ is the velocity of ATP-dependent glutamate uptake, $[\mathrm{S}]$ is the concentration of glutamate in $\mathrm{mM}$, and $V_{\max }$ and $\mathrm{K}_{\mathrm{m}}$ are the MichaelisMenten constants for the maximal initial velocity and half-maximal concentration of glutamate, respectively.

\section{Results}

Time course studies of glutamate uptake in crude synaptic vesicles from five classes of vertebrates

Synaptic vesicles were isolated from the brains of rats, pigeons, turtles, frogs, and goldfish, which represent the five classes of vertebrates: mammals, avians, reptiles, amphibians, and fish. Glutamate uptake into these vesicles was measured in the presence and absence of $2 \mathrm{~mm}$ ATP (Fig. 1). All five of these species exhibit ATP-dependent glutamate uptake into synaptic vesicles in a manner that is consistent with that first described for bovine synaptic vesicles (Naito and Ueda, 1983). The time required to reach steady state varies among the species from 10 to $30 \mathrm{~min}$, and the levels obtained at steady state differ substantially, but all five species display a 10-20-fold stimulation of uptake by ATP.

\section{Effect of chloride on glutamate uptake activity}

At concentrations of 1-10 mM, chloride stimulates glutamate uptake into bovine (Naito and Ueda, 1985), mouse (FischerBovenkerk et al., 1988), and rat (Kish and Ueda, 1989; Hell et al., 1990) synaptic vesicles three- to fivefold, while concentrations above $10 \mathrm{~mm}$ show little stimulation or even inhibition. We have examined the effect of chloride on glutamate uptake in synaptic vesicles from other vertebrate species (Fig. 2). Low- millimolar concentrations of chloride stimulated uptake in all five species tested. When compared to a control experiment using potassium isethionate, a nonpermeant anion (data not shown), 2-4 mM chloride caused from a 3.3-fold stimulation in rat and goldfish vesicles to almost a sixfold stimulation in turtle and pigeon vesicles. Also, concentrations of chloride above 10 mM display a diminished ability to stimulate uptake, similar to that shown previously for rat, mouse, and bovine vesicles (Naito and Ueda, 1985; Fischer-Bovenkerk et al., 1988; Kish and Ueda, 1989).

\section{Effect of glutamate analogs, agonists, and related amino acids}

The glutamate translocator present in bovine and rat synaptic vesicles has been shown to be quite specific for glutamate (Naito and Ueda, 1985; Kish and Ueda, 1989). It does not transport L- or D-aspartate and displays stereoselectivity for L-glutamate over D-glutamate. It also has no affinity for other neurotransmitter amino acids such as glycine or GABA or for glutamate receptor agonists.

The effects of these reagents were tested on the various synaptic vesicle uptake systems, and similar results were seen (Table 1). When tested at $5 \mathrm{~mm}$ (on the uptake of $0.5 \mathrm{~mm}$ glutamate in all species and on $0.05 \mathrm{~mm}$ glutamate in turtle and frog), L-glutamate was more effective than D-glutamate in reducing the uptake of ${ }^{3} \mathrm{H}$-L-glutamate, in all the species tested. Of the other amino acids and glutamate analogs tested, only $\alpha$-methylglutamate and $\gamma$-methylene glutamate were potent inhibitors, both of which have been previously shown to inhibit glutamate uptake in mammalian vesicles (Naito and Ueda, 1985; Kish and Ueda, 1989). D- and L-aspartate, which have only one less methylene group in their carbon backbone, show little affinity for the vesicular glutamate transport system. This is interesting because both $\mathrm{D}$ - and L-aspartate are transported by the plasma membrane glutamate transporter (Christensen and Makowske, 1983). Also, glutamine, $\alpha$-ketoglutarate, and the neurotransmitter amino acids glycine and GABA had little effect on the uptake of glutamate in any of these species.

The glutamate analogs NMDA, quisqualate, and kainate strongly interact with various glutamate receptors. In previous studies, these agents showed no inhibition of glutamate uptake in mammalian vesicles (Naito and Ueda, 1985; Kish and Ueda, 1989). When these agents were tested in the various species, they had no effect in rat, turtle, frog, and goldfish and had only a very slight effect in pigeon vesicles. The results from these analog studies suggest that the specificity of the glutamate translocator remains largely unchanged during the evolution from fish to mammals.

To further demonstrate that the patterns described above represent the true inhibitory potential of these neurotransmitter amino acids and glutamate analogs, the same agents were tested in frog and turtle vesicles (and can be compared to rat and bovine vesicles in Kish and Ueda, 1989, their Table III) using the same inhibitor concentration and tenfold less glutamate (Table 1). The results show a very similar pattern to those seen with 0.5 mM glutamate: L-glutamate is preferred over D-glutamate, and only $\alpha$-methylglutamate and $\gamma$-methylene glutamate display significant inhibition of glutamate uptake.

\section{Effect of membrane-potential-dissipating agents, ATPase inhibitors, and other agents}

The vesicular uptake of glutamate (Naito and Ueda, 1985; Maycox et al., 1988; Shioi et al., 1989), glycine (Kish et al., 1989), 
Figure 1. Time courses of ${ }^{3} \mathrm{H}$-glutamate uptake into crude synaptic vesicles from goldfish, frog, turtle, pigeon, and rat brains. Crude synaptic vesicles from goldfish (triangles), frog (circles), turtle (simple squares), pigeon (diamonds), and rat (squares with center dots) brains were incubated for various times with $0.5 \mathrm{mM}^{3} \mathrm{H}$-glutamate in the absence (open symbols, broken lines) or presence (solid symbols, solid lines) of 2 mм ATP. The uptake reaction was stopped at the indicated times, and the amount of ${ }^{3} \mathrm{H}$-glutamate taken up into the vesicles was determined in triplicate as described in Materials and Methods. The variation as measured by the SD was less than $5 \%$ of the uptake values for all data points.

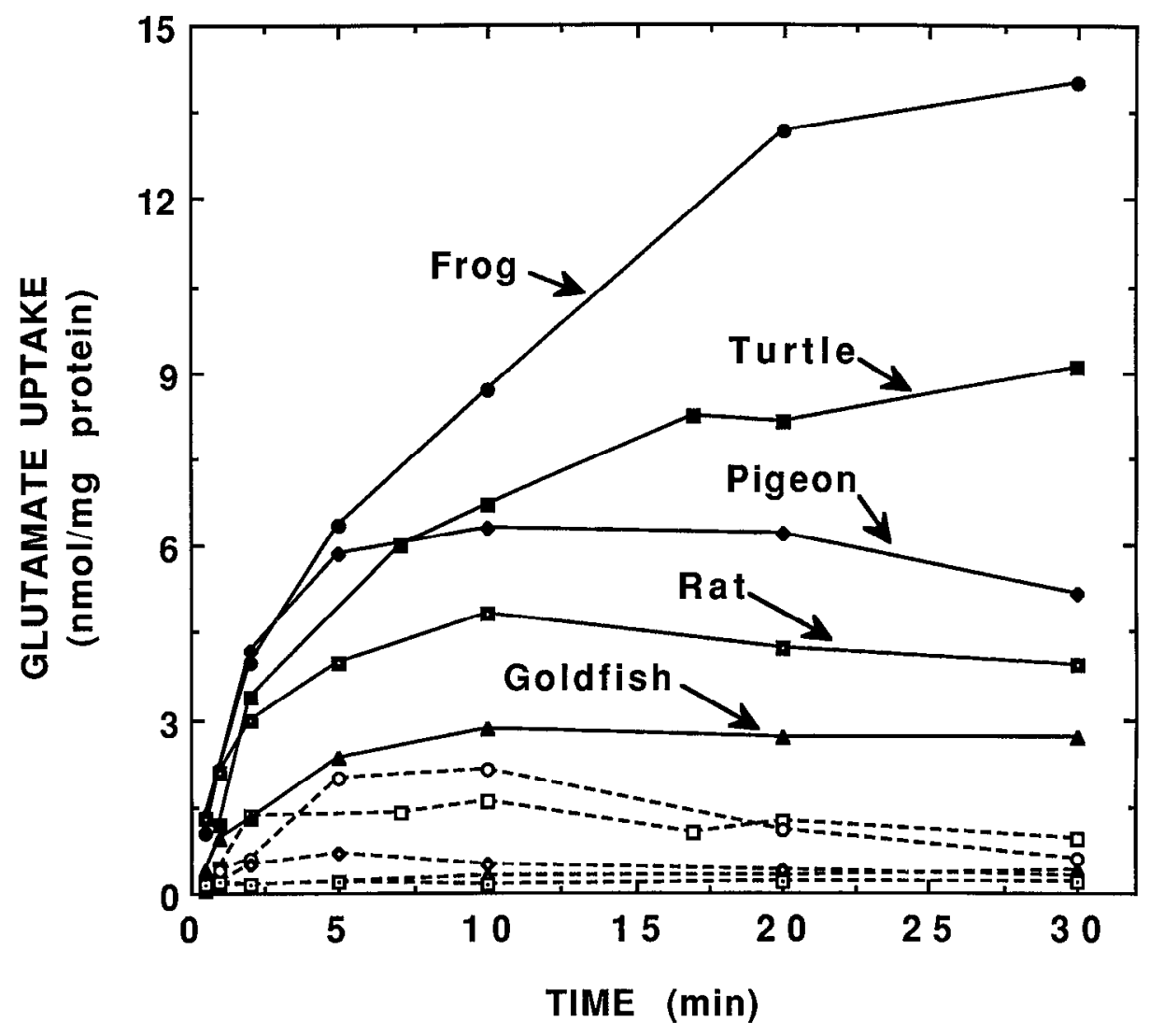

This agent also inhibited glutamate uptake into turtle, frog, pigeon, and goldfish vesicles. 3-Phosphoglycerate (3-PG), a glycolytic intermediate, has been found specifically to stimulate glutamate uptake (2-phosphoglycerate and other glycolytic intermediates do not stimulate glutamate uptake) into rat synaptic vesicles by as much as $100 \%$ (M. Feng and T. Ueda, unpublished observations). When 3-PG was tested, it was found to stimulate glutamate uptake on all five species, from about $20 \%$ up to almost $100 \%$.

\section{Michaelis-Menten kinetics of glutamate uptake}

To determine whether the affinity of the glutamate translocator for glutamate has changed during evolution from fish to mammals, the concentration of glutamate was varied, and the initial rate of uptake was measured (Table 2). The transport of glutamate into both intact bovine synaptic vesicles and reconstituted rat vesicles has been shown to follow a classical saturable kinetic profile (Naito and Ueda, 1985; Carlson et al., 1989b) displaying a single $\mathrm{K}_{\mathrm{m}}$ of about 1.6-2.0 mM. The values obtained from these species ranged from about $0.7 \mathrm{~mm}$ for pigeon vesicles to about $1.7 \mathrm{~mm}$ for turtle vesicles. The $V_{\max }$ for the initial uptake of glutamate uptake varied quite extensively among the species tested. Goldfish vesicles showed the lowest steady-state level of uptake but had the highest $V_{\max }$ (over $7 \mathrm{nmol} / \mathrm{mg}$ protein $/ \mathrm{min}$ ). In contrast, turtle vesicles displayed the second-highest steadystate level of uptake (Fig. 1), but the $V_{\max }$ was the lowest (1.66 $\mathrm{nmol} / \mathrm{mg}$ protein/min).

\section{Glutamate uptake in synaptic vesicles from invertebrates}

A synaptic vesicle fraction was also prepared from two invertebrates: the major neural ganglion of the crayfish and the heads, abdomens, and thoraxes of Drosophila. No ATP-dependent gluergot tripeptide that has been shown to inhibit glutamate uplake competitively in rat synaptic vesicles (Carlson et al., 1989a). 


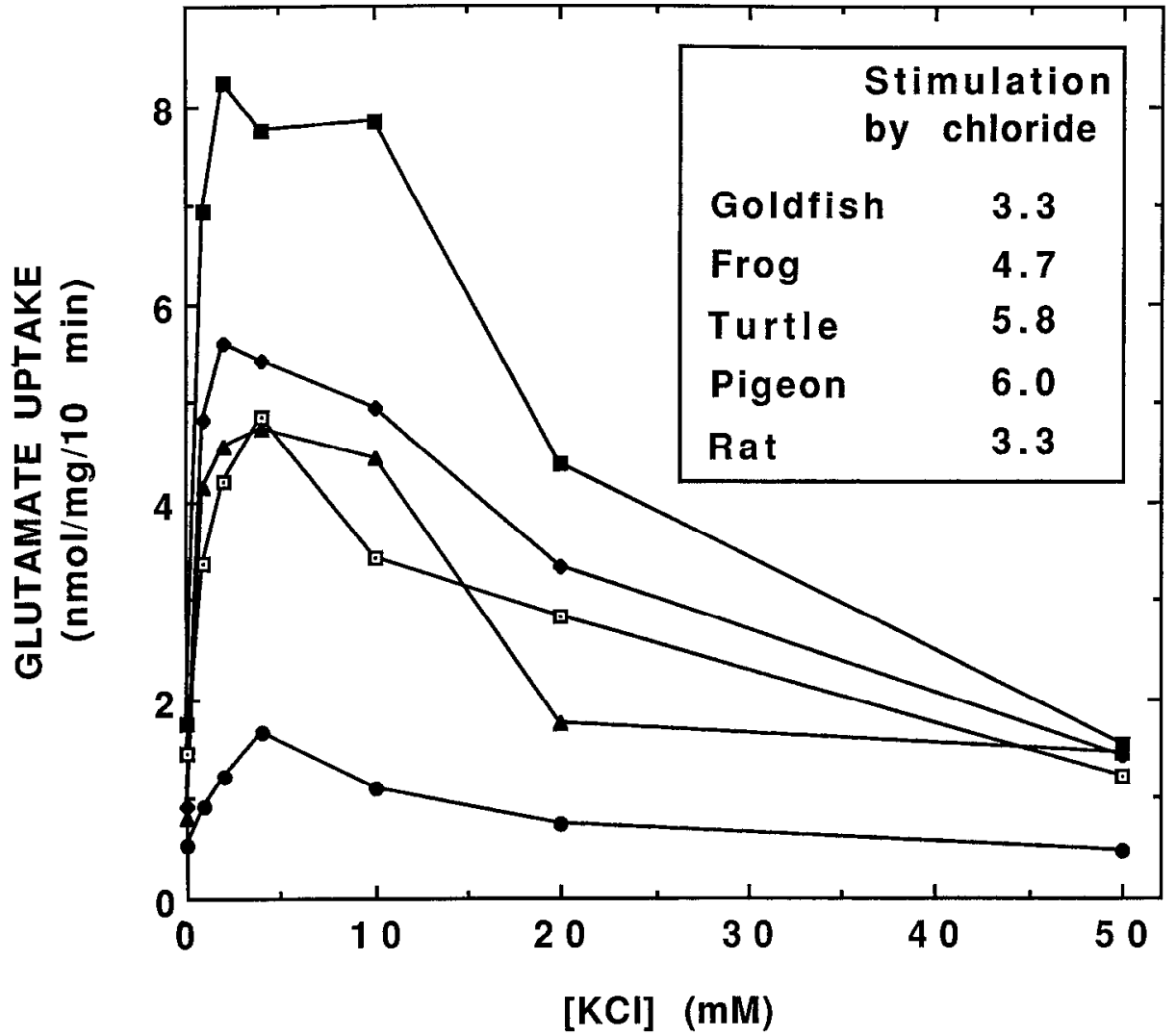

Figure 2. Effects of $\mathrm{KCl}$ on ATP-dependent ${ }^{3} \mathrm{H}$-glutamate uptake into crude synaptic vesicles from various vertebrate brains. Crude synaptic vesicles from goldfish (O), frog $(\square)$, turtle $(\bullet)$, pigeon $(\boldsymbol{\Lambda})$, and rat $(\square)$ brains were incubated with varying concentrations of $\mathrm{KCl}$, and the uptake of $0.5 \mathrm{~mm}^{3} \mathrm{H}$-glutamate was measured for $10 \mathrm{~min}$ in the presence or absence of $2 \mathrm{mM}$ ATP. The numbers in the inset represent the average of triplicate determinations of the ATP-dependent glutamate uptake activity into the vesicles. The variation as measured by the SD was less than $5 \%$ of the uptake values for all data points. Vesicles incubated under identical conditions using potassium isethionate instead of $\mathrm{KCl}$ showed no difference in uptake activity from those vesicles incubated without $\mathrm{KCl}$ (data not shown). The values presented for the stimulation by chloride represent the maximal-fold stimulation of glutamate uptake by $\mathrm{KCl}$. tamate uptake could be measured in these vesicle fractions, at either low $(5 \mu \mathrm{M})$ or high $(500 \mu \mathrm{M})$ concentrations of glutamate.

\section{Discussion}

In this study, we have examined the major functional characteristics of glutamate uptake into brain synaptic vesicles and have found that these characteristics remain virtually unchanged among the major classes of vertebrates.

The uptake of several neurotransmitters such as glutamate, GABA, and glycine into mammalian brain vesicles (Naito and Ueda, 1985; Fykse and Fonnum, 1988; Hell et al., 1988; Kish et al., 1989), catecholamines into both mammalian brain vesicles and chromaffin granules (Toll et al., 1977), and ACh into Torpedo electric organ vesicles (Anderson et al., 1982) has been previously shown to be ATP dependent. We found this also to be the case with glutamate uptake into vesicles from avian (pigeon), reptilian (turtle), amphibian (bullfrog), and fish (goldfish) brain. The final steady-state levels of glutamate obtained in the vesicles from the various vertebrates varied greatly (Fig. 1). Variation in steady-state glutamate levels may be a function of the following vesicle characteristics: the vesicle size, the vesicular $\mathrm{H}^{+}$-pump ATPase activity, or the vesicle population density in the vesicle fraction. The initial rate of uptake as expressed by the $V_{\max }$ of uptake also varied to a large extent among the species tested (Table 2). These differences in $V_{\max }$ may reflect variations in the catalytic turnover rate of the glutamate transport proteins, the number of transport proteins present per vesicle, or again, the vesicle population density in the vesicle fraction. It is unknown at this time which of these vesicle characteristics is responsible for the differences seen in either the steady-state level of glutamate or the $V_{\max }$ of glutamate uptake.
The uptake of glutamate into mammalian vesicles has been unequivocally demonstrated to be stimulated by low concentrations of chloride; it is typically stimulated three- to fivefold by $2-4 \mathrm{mM}$ concentrations of chloride. This is in contrast to the uptake of glycine into synaptic vesicles (Kish et al., 1989), which is stimulated only slightly by 5 to $10 \mathrm{~mm}$ chloride, or that of GABA, which has been shown to be unaffected by millimolar concentrations of chloride (Fykse et al., 1989; Kish et al., 1989). This study shows that, in all of the species where glutamate uptake was observed, it was stimulated by $2-4 \mathrm{~mm}$ chloride. While the function of this stimulation is unclear, it is apparent from this study that the stimulatory effect of chloride is conserved among vertebrates, and this conservation suggests that the intracellular levels of chloride at the nerve terminal may play an important role in regulating the storage of glutamate within the synaptic vesicle.

The synaptic vesicle glutamate transport system is remarkably selective for the amino acid glutamate. Molecules that differ by as little as a single methylene group (such as aspartate or $\alpha$-aminoadipate) are not recognized by the glutamate transporter (Naito and Ueda, 1985; Kish and Ueda, 1989). This selectivity of the transporter also appears to be strongly conserved throughout vertebrate evolution (Table 1). In all of the species tested, neither the neurotransmitter amino acids glycine and GABA nor aspartate isomers significantly inhibited glutamate uptake. Only $\alpha$-methyl glutamate and $\gamma$-methylene glutamate inhibited vesicular glutamate uptake, and this inhibition was consistent among all of the species examined. The glutamate receptor agonists (NMDA, kainate, and quisqualate) did not inhibit glutamate uptake activity in most of the vertebrates tested. Two patterns were noticed in the inhibition patterns presented in Table 1. First, the glutamate uptake into rat vesicles showed 
Table 1. Effects of glutamate analogs and agonists, ATPase inhibitors, and other compounds on glutamate uptake into crude synaptic vesicles from various species

Percent of control ATP-dependent uptake

\begin{tabular}{|c|c|c|c|c|c|c|c|}
\hline Test agents $^{a}$ & Goldfish & Frog & $(\text { Frog })^{b}$ & Turtle & (Turtle) $^{b}$ & Pigeon & Rat \\
\hline \multicolumn{8}{|l|}{ Amino acids and analogs } \\
\hline Control $^{c}$ & $(1.74 \pm 0.09)$ & $(10.0 \pm 0.2)$ & $(1.2 \pm 0.1)$ & $(6.2 \pm 0.1)$ & $(0.7 \pm 0.04)$ & $(4.8 \pm 0.2)$ & $(4.2 \pm 0.3)$ \\
\hline L-Glutamate & $19 \pm 3$ & $13 \pm 3$ & $(4 \pm 1)$ & $8 \pm 5$ & $(2 \pm 4)$ & $30 \pm 2$ & $25 \pm 2$ \\
\hline D-Glutamate & $41 \pm 2$ & $39 \pm 2$ & $(29 \pm 3)$ & $31 \pm 5$ & $(15 \pm 3)$ & $55 \pm 3$ & $66 \pm 4$ \\
\hline L-Aspartate & $95 \pm 5$ & $114 \pm 6$ & $(96 \pm 3)$ & $88 \pm 4$ & $(90 \pm 3)$ & $71 \pm 3$ & $101 \pm 4$ \\
\hline D-Aspartate & $101 \pm 5$ & $107 \pm 4$ & $(97 \pm 2)$ & $98 \pm 4$ & $(88 \pm 5)$ & $92 \pm 5$ & $102 \pm 4$ \\
\hline$\alpha$-Methyl-DL-glutamate & $28 \pm 4$ & $23 \pm 2$ & $(14 \pm 1)$ & $22 \pm 5$ & $(19 \pm 4)$ & $35 \pm 3$ & $42 \pm 6$ \\
\hline$\gamma$-Methylene-DL-glutamate & $41 \pm 4$ & $31 \pm 3$ & $(22 \pm 4)$ & $26 \pm 1$ & $(16 \pm 2)$ & $44 \pm 3$ & $50 \pm 4$ \\
\hline L-Glutamine & $87 \pm 6$ & $100 \pm 3$ & $(90 \pm 5)$ & $97 \pm 4$ & $(87 \pm 5)$ & $78 \pm 4$ & $97 \pm 2$ \\
\hline$\alpha$-Ketoglutarate & $110 \pm 5$ & $101 \pm 5$ & $(99 \pm 2)$ & $92 \pm 4$ & $(85 \pm 6)$ & $97 \pm 2$ & $102 \pm 4$ \\
\hline$\gamma$-Aminobutyrate (10 mM) & $114 \pm 2$ & ND & (ND) & $85 \pm 6$ & (ND) & $91 \pm 2$ & $106 \pm 3$ \\
\hline Glycine (10 mm) & $114+4$ & ND & (ND) & $84 \pm 4$ & (ND) & $99 \pm 1$ & $101 \pm 0$ \\
\hline \multicolumn{8}{|l|}{ Glutamate receptor agonists } \\
\hline NMDA & $100 \pm 1$ & $113 \pm 5$ & $(101 \pm 4)$ & $96 \pm 3$ & $(95 \pm 5)$ & $81 \pm 3$ & $101 \pm 2$ \\
\hline Kainate & $110 \pm 2$ & $95 \pm 3$ & $(98 \pm 3)$ & $90 \pm 3$ & $(91 \pm 6)$ & $81 \pm 4$ & $104 \pm 2$ \\
\hline Quisqualate & $92 \pm 5$ & $100 \pm 1$ & $(95 \pm 5)$ & $92 \pm 4$ & $(91 \pm 3)$ & $86 \pm 3$ & $124 \pm 6$ \\
\hline \multicolumn{8}{|c|}{ ATPase inhibitors/membrane-potential dissipators } \\
\hline $\mathrm{FCCP}(10 \mu \mathrm{M})^{d}$ & $0 \pm 1$ & $0 \pm 2$ & $(0 \pm 1)$ & $0 \pm 0$ & $(0 \pm 1)$ & $0 \pm 2$ & $0 \pm 3$ \\
\hline Oligomycin $(2.5 \mu \mathrm{g} / \mathrm{ml})^{d}$ & $107 \pm 5$ & ND & $(101 \pm 3)$ & $114 \pm 3$ & $(98 \pm 4)$ & $110 \pm 3$ & $99 \pm 1$ \\
\hline Ouabain (1 mM) & $99 \pm 2$ & ND & $(98 \pm 2)$ & $106 \pm 4$ & $(100 \pm 2)$ & $103 \pm 4$ & $100 \pm 2$ \\
\hline Vanadatc $(0.5 \mathrm{mM})$ & $109 \pm 4$ & ND & $(109 \pm 4)$ & $100 \pm 1$ & $(101 \pm 3)$ & $113 \pm 6$ & $113 \pm 5$ \\
\hline NEM (0.1 mm) & $4 \pm 2$ & $1 \pm 2$ & $(3 \pm 4)$ & $0 \pm 3$ & $(3 \pm 1)$ & $7 \pm 4$ & $4 \pm 3$ \\
\hline Bafilomycin $(1 \mu \mathrm{M})^{d}$ & $6 \pm 4$ & ND & $(2 \pm 3)$ & $4 \pm 3$ & $(7 \pm 2)$ & $8 \pm 2$ & $2 \pm 3$ \\
\hline \multicolumn{8}{|l|}{ Modulatory agents } \\
\hline Bromocriptine $(0.1 \mathrm{~mm})^{d}$ & $44 \pm 2$ & $31 \pm 3$ & $(36 \pm 3)$ & $41 \pm 2$ & $(39 \pm 2)$ & $50 \pm 5$ & $30 \pm 2$ \\
\hline $3-P(1 \mathrm{~mm})$ & $122 \pm 6$ & $130 \pm 4$ & $(109 \pm 4)$ & $158 \pm 3$ & $(160 \pm 5)$ & $132 \pm 5$ & $190 \pm 4$ \\
\hline
\end{tabular}

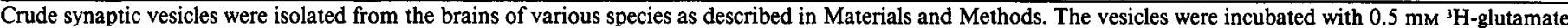

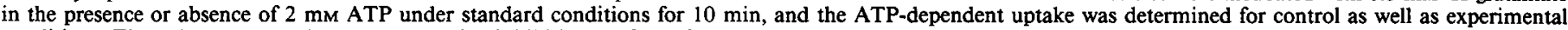

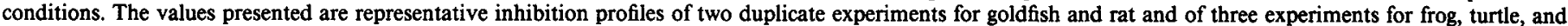

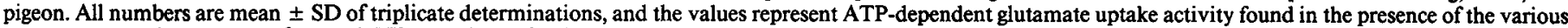
agents, expressed as percent of control. ND, not determined.

a Concentration of test agents was $5 \mathrm{~mm}$ unless otherwise indicated.

${ }^{b}$ Vesicles were incubated with $0.05 \mathrm{mM}{ }^{3} \mathrm{H}$-glutamate instead of $0.5 \mathrm{~mm}{ }^{3} \mathrm{H}$-glutamate.

'Control values are expressed as ATP-dependent uptake activity ( $\mathrm{nmol} / \mathrm{mg}$ protein $/ 10 \mathrm{~min}$ ).

${ }^{d}$ Both control and experimental conditions were tested in the presence of $1.0 \%$ dimethylsulfoxide, which reduced controls by $10-12 \%$.

the strongest preference for glutamate as seen by weaker inhibition of uptake by D-glutamate, D- and L-aspartate, $\alpha$-methyl glutamate, and $\gamma$-methylene glutamate, as well as the strongest stimulation by 3-PG. Second, the uptake of glutamate by pigeon vesicles was reduced $15-20 \%$ by both glutamine and the receptor agonists NMDA, kainate, and quisqualate. These variations in substrate-inhibitor interactions may denote minor structural differences in the active site of these glutamate transporters, when compared to the other vertebrate transporters.

The exclusion of glutamate receptor agonists, metabolic intermediates, and aspartate isomers by the vesicular glutamate transporter suggests that the recognition sites for the $\gamma$-carbonyl group, the $\alpha$-amino group, and the five-carbon chain of glutamate are strictly conserved throughout vertebrate evolution. The structural conservation of the glutamate transporter is further demonstrated by the universal effect of 4-bromocriptine, a competitive inhibitor of ATP-dependent glutamate uptake (Carlson et al., 1989a), among vertebrate species tested.

Not only is the structural nature of the active site of this translocator conserved, but the translocator's affinity of glutamate is conserved, as well. Table 2 displays the kinetic param- eters for glutamate uptake into the vesicles of various vertebrates studied. While some variation is seen in the $K_{m}$ values, these numbers are rather similar when compared to the values reported for the sodium-dependent uptake system in the plasma membrane (3-20 $\mu \mathrm{M}$; Logan and Snyder, 1972; Kanner and Sharon, 1978), or the $K_{d}$ values reported for glutamate binding to its receptors (10 $\mathrm{nM}$ to $2.5 \mu \mathrm{M}$; Foster and Fagg, 1984). The $V_{\max }$ values for glutamate uptake generated from these experiments varied considerably among the species tested.

It is worth noting that there appears to be an approximate inverse relationship between the $V_{\max }$ for the initial rate of glutamate uptake (Table 2) and the amount of glutamate retained in the vesicle at steady state (Fig. 1). Species such as goldfish, which display a low steady-state level of glutamate, also display a high $V_{\max }$ for uptakc. Conversely, species such as frogs show a high steady-state level of glutamate and a relatively low $V_{\max }$ value. These findings may suggest that evolution regulates the internal amount of glutamate by adjusting the vesicular capacity for glutamate and the initial rate of glutamate uptake into the vesicle.

Along with chloride stimulation, substrate/inhibitor specific- 


\begin{tabular}{lll}
\hline $\begin{array}{l}\text { Table 2. } \\
\text { vesicles }\end{array}$ & Kinetic parameters for glutamate uptake into crude synaptic \\
Species & $\mathrm{K}_{\mathrm{m}}(\mathrm{mM})$ & $V_{\max }(\mathrm{nmol} / \mathrm{mg}$ protein/min) \\
\hline Rat & $1.65 \pm 0.12$ & $5.96 \pm 0.11$ \\
Pigeon & $0.71 \pm 0.03$ & $4.40 \pm 0.06$ \\
Turtle & $1.70 \pm 0.24$ & $1.67 \pm 0.09$ \\
Frog & $1.39 \perp 0.54$ & $3.76 \pm 0.07$ \\
Goldfish & $1.26 \pm 0.12$ & $7.02 \pm 0.27$
\end{tabular}

Crude synaptic vesicles from the brains of various species were incubated for min with varying concentrations of ${ }^{3} \mathrm{H}$-glutamate in the presence or absence of 2 mM ATP. The $\mathrm{K}_{\mathrm{m}}, V_{\max }$, and error values were determined from single experiments and were assayed in triplicate by least-squarcs analysis as described under Materials and Methods. Variability is presented as calculated variance.

ity, and substrate affinity, it also appears that the type of ATPase responsible for providing the energy for glutamate uptake in brain synaptic vesicles is conserved among vertebrates. Only NEM and bafilomycin, inhibitors of V-type ATPases, eliminated vesicular glutamate uptake (Table 1), whereas inhibitors of F-type (oligomycin) and P-type ATPase (ouabain and orthovanadate) did not affect glutamate uptake. It should also be noted that the stimulation of 3-PG on ATP-dependent glutamate uptake is also conserved, though the degree of stimulation is variable among these species.

Attempts to demonstrate ATP-dependent glutamate uptake in synaptic vesicles from invertebrates such as crayfish and Drosophila were not successful. It is well documented that glutamate is a neurotransmitter at the invertebrate neuromuscular junction (Sansom and Usherwood, 1986), but its role in the invertebrate CNS has not been established. While glutamate receptors have been found in Drosophila heads (Fielder et al., 1986), it might be that the levels of glutamatergic neurons in the central nervous ganglia of invertebrates are too low for us to detect glutamate uptake with our transport assay. Alternatively, it is possible that invertebrate central nervous ganglia might utilize a different mcchanism for the accumulation of glutamate into synaptic vesicles, if glutamate serves as a neurotransmitter in these ganglia. It is also possible that vesicles from invertebrates lack a glutamate transport system altogether.

The results presented in this study clearly show that the uptake of glutamate into brain synaptic vesicles is conserved throughout vertebrate classes. All of the major functional characteristics of vesicular glutamate transport, such as ATP dependencc, chloride stimulation, substrate specificity, substrate affinity, and mode of energization, are similar among the vertebrate species tested. This suggests that the mechanism of vesicular glutamate transport has remained conserved for at least $350-400$ million years, from the evolution of boney fish through the evolution of mammals. This well-conserved nature further supports the concept (Ueda, 1986) that the vesicular active transport system specific for glutamate plays a pivotal role in selecting glutamate for synaptic release as a neurotransmitter in the vertebrate CNS.

\section{References}

Anderson DC, King SC, Parsons SM (1982) Proton gradient linkage to active uptake of $\left[{ }^{3} \mathrm{H}\right]$-acetylcholine by Torpedo electric organ synaptic vesicles. Biochemistry 21:3037-3043.

Bowman EJ, Siebers A, Altendorf K (1988) Bafilomycins: a class of inhibitors of membrane ATPases from microorganisms, animal cells, and plant cells. Proc Natl Acad Sci 85:7972-7976.
Carlson MD, Ueda T (1990) Accumulated glutamate levels in the synaptic vesicle are not maintained in the absence of active transport. Neurosci Lett 110:325-330.

Carlson MD, Kish PE, Ueda T (1989a) Glutamate uptake into synaptic vesicles: competitive inhibition by bromocriptine. J Neurochem 53: 1889-1894.

Carlson MD, Kish PE, Ueda T (1989b) Characterization of the solubilized and reconstituted ATP-dependent vesicular glutamate uptake system. J Biol Chem 264:7369-7376.

Christensen HN, Makowske M (1983) Recognition chemistry of anionic amino acids for hepatocyte transport and for neurotransmittory action compared. Life Sci 33:2255-2267.

Cidon S, Nelson N (1986) Purification of $N$-ethylmaleimide sensitive ATPase from chromaffin granule membranes. J Biol Chem 261:92229227.

Cidon $\mathrm{S}$, Sihra TS (1989) Characterization of a $\mathrm{H}^{+}-\mathrm{ATPase}$ in rat brain synaptic vesicles. J Biol Chem 264:8281-8288.

Cleland WW (1979) Statistical analysis of enzyme kinetic data. Methods Enzymol 63:103-138.

Fielder JL, Inestrosa NC, Bustos G (1986) Putative glutamate receptors in membranes obtained from Drosophila melanogaster. J Neurosci Res 16:505-515.

Fischer-Bovenkerk C, Kish PE, Ueda T (1988) ATP-dependent glutamate uptake into synaptic vesicles from cerebellar mutant mice. $J$ Neurochem 42:1054-1059.

Floor E, Leventhal PS, Schaffer SF (1990) Partial purification and characterization of the vacuolar $\mathrm{H}^{+}$-ATPase of mammalian synaptic vesicles. J Neurochem 55:1663-1670.

Foster AC, Fagg GE (1984) Acidic acid binding sites in mammalian neuronal membranes: their characteristics and relationship to synaptic receptors. Brain Res 319:103-164.

Fykse EM, Fonnum F (1988) Uptake of $\gamma$-aminobutyric acid by a synaptic vesicle fraction isolated from rat brain. J Neurochem 50: $1237-1242$.

Fykse EM, Christensen H, Fonnum F (1989) Comparison of the properties of $\gamma$-aminobutyric acid and L-glutamate uptake into synaptic vesicles isolated from rat brain. J Neurochem 52:946-951.

Hell JW, Maycox PR, Stadler H, Jahn R (1988) Uptake of GABA by rat synaptic vesicles isolated by a new procedure. EMBO J 7:30233029.

Hell JW, Maycox PR, Jahn R (1990) Energy dependence and functional reconstitution of the $\gamma$-aminobutyric acid carrier from synaptic vesicles. J Biol Chem 265:2111-2117.

Kanner BI, Sharon I (1978) Active transport of L-glutamate by membrane vesicles isolated from rat brain. Biochemistry 17:3949-3953.

Kish PE, Ueda T (1989) Glutamate accumulation into synaptic vesicles. Methods Enzymol 174:9-25.

Kish PE, Ueda T (1991) Calcium-dependent release of accumulated glutamate from synaptic vesicles within permeabilized nerve terminals. Neurosci Lett 122:179-182.

Kish PE, Fischer-Bovenkerk C, Ueda T (1989) Active transport of $\gamma$-aminobutyric acid and glycine into synaptic vesicles. Proc Natl Acad Sci USA 86:3877-3881.

Logan WJ, Snyder SH (1972) High affinity uptake systems for glycine, glutamic acid and aspartic acids in synaptosomes of rat central nervous tissues. Brain Res 42:413-431.

Lowry OH, Rosebrough NJ, Farr AL, Randall RJ (1951) Protein measurement with the Folin phenol reagent. J Biol Chem 193:265275.

Maycox PR, Deckworth T, Hell JW, Jahn R (1988) Glutamate uptake by brain synaptic vesicles. J Biol Chem 263:15423-15428.

Moriyama Y, Nelson N (1989a) Lysosomal $\mathrm{H}^{+}$-translocating ATPase has a similar subunit structure to chromaffin granule $\mathrm{H}^{+}$-ATPase complex. Biochem Biophys Acta 980:241-247.

Moriyama $\mathrm{Y}$, Nelson N (1989b) $\mathrm{H}^{+}$-translocating ATPase in Golgi apparatus. J Biol Chem 264:18445-18450.

Naito S, Ueda T (1983) Adenosine triphosphate-dependent uptake of glutamate into protein I-associated synaptic vesicles. J Biol Chem 258:696-699.

Naito S, Ueda T (1985) Characterization of glutamate uptake into synaptic vesicles. J Neurochem 44:99-109.

Nicholls DG, Sihra TS (1986) Synaptosomes possess an exocytotic pool of glutamate. Nature 321:772-773.

Petersen PL, Carafoli E (1987) Ion motive ATPases. I. Ubiquity, properties, and significance to cell function. Trends Biochem Sci 12: $146-150$. 
Philippu A, Beyer J (1973) Dopamine and noradrenaline transport into subcellular vesicles of the striatum. Naunyn-Schmiedebergs Arch Pharmacol 278:387-402.

Sansom MSP, Usherwood PNR (1986) L-Glutamic acid receptors on locust muscle: pharmacological properties and single receptor channel studies. In: Excitatory amino acids (Roberts PJ, Storm-Mathisen J, Bradford HF, eds), pp 251-262. London: Macmillan.

Shioi J, Naito S, Ueda T (1989) Glutamate uptake into synaptic vesicles of bovine cerebral cortex and electrochemical potential difference of proton across the membrane. Biochem J 258:499-504.

Toll L, Gundersen CB, Howard BD (1977) Energy utilization in the uptake of catecholamines by synaptic vesicles and adrenal chromaffin granules. Brain Res 136:59-66.

Ueda T (1986) Glutamate transport in synaptic vesicles. In: Excitatory amino acids (Roberts P, Storm-Mathisen J, Bradford HF, eds), pp 173-195. London: Macmillan.

Yamagata SK, Parsons SM (1989) Cholinergic synaptic vesicles contain a V-type and a P-type ATPase. J Neurochem 53:1354-1362. 